\title{
The Importance of Being "That" Colorectal pT1: A Combined Clinico-Pathological Predictive Score to Improve Nodal Risk Stratification
}

\author{
Alessandro Gambella ${ }^{1 \dagger}$, Enrico Costantino Falco ${ }^{1 \dagger}$, Giacomo Benazzo ${ }^{1}$, \\ Simona Osella-Abate ${ }^{2}$, Rebecca Senetta ${ }^{3}$, Isabella Castellano ${ }^{1}$, Luca Bertero ${ }^{1 *}$ and \\ Paola Cassoni ${ }^{1}$ \\ ${ }^{1}$ Pathology Unit, Department of Medical Sciences, University of Turin, Turin, Italy, ${ }^{2}$ Molecular Pathology Unit, "Città della \\ Salute e della Scienza di Torino" University Hospital, Turin, Italy, ${ }^{3}$ Pathology Unit, Department of Oncology, University of Turin, \\ Turin, Italy
}

OPEN ACCESS

Edited by:

Qi Liu,

Fudan University, China

Reviewed by:

Valeria Barresi,

University of Verona, Italy Antonio leni,

University of Messina, Italy

*Correspondence: Luca Bertero

luca.bertero@unito.it

tThese authors have contributed equally to this work and share first authorship

Specialty section

This article was submitted to

Gastroenterology,

a section of the journal

Frontiers in Medicine

Received: 17 December 2021

Accepted: 14 January 2022

Published: 14 February 2022

Citation:

Gambella A, Falco EC, Benazzo G,

Osella-Abate S, Senetta $R$, Castellano I, Bertero $L$ and Cassoni $P$ (2022) The Importance of Being "That"

Colorectal PT1: A Combined Clinico-Pathological Predictive Score to Improve Nodal Risk Stratification.

Front. Med. 9:837876.

doi: 10.3389/fmed.2022.837876
The management of endoscopically resected pT1 colorectal cancer $(\mathrm{CRC})$ relies on nodal metastasis risk estimation based on the assessment of specific histopathological features. Avoiding the overtreatment of metastasis-free patients represents a crucial unmet clinical need. By analyzing a consecutive series of 207 pT1 CRCs treated with colectomy and lymphadenectomy, this study aimed to develop a novel clinicopathological score to improve pT1 CRC metastasis prediction. First, we established the clinicopathological profile of metastatic cases: Iymphovascular invasion (OR: 23.8; Cl: 5.12-110.9) and high-grade tumor budding (OR: 5.21; Cl: 1.60-16.8) correlated with an increased risk of nodal metastasis, while age at diagnosis >65 years (OR: 0.26; $\mathrm{Cl}$ : 0.09-0.71) and high tumor-infiltrating lymphocytes (OR: 0.19; Cl: 0.06-0.59) showed a protective effect. Combining these features, we built a five-tier risk score that, applied to our series, identified cases with a higher risk (score $\geq 2$ ) of nodal metastasis (OR: 7.7; Cl: 2.4-24.4). Notably, a score of 0 was only assigned to cases with no metastases (13/13 cases) and all the score 4 samples (2/2 cases) showed nodal metastases. In conclusion, we developed an effectively combined score to assess pT1 CRC nodal metastasis risk. We believe that its adoption within a multidisciplinary pT1 unit could improve patients' clinical management and limit surgical overtreatment.

Keywords: colorectal carcinoma, pT1, lymph node metastasis, predictive score, age at diagnosis, tumor budding, lymphovascular invasion, tumor-infiltrating lymphocytes

\section{INTRODUCTION}

Screening programs improved the early detection of colorectal cancers (CRCs) (1-5) but raised a new clinical issue: the management of endoscopically resected pT1 colorectal tumors (pT1 CRC).

According to the Tumor Node Metastasis (TNM) classification of malignant tumors, pT1 CRC is defined by the presence of submucosal invasion and represents the earliest stage with metastatic potential (6). Specifically, nodal metastasis in this setting has been reported in up to $15 \%$ of pT1 CRC cases $(7,8)$. 
Following pT1 CRC endoscopic resection, two different approaches can be undertaken: either conservative endoscopic follow-up $(9,10)$ or surgical resection enabling nodal status assessment (11-13). This choice is guided by the risk of node metastasis which is estimated according to specific histopathological parameters which stratify these tumors in lowand high-risk pT1 CRC $(14,15)$. The ultimate clinical aim is to balance staging/therapeutic benefits with surgical risks and consequences $(16,17)$.

Regarding the analyzed histopathological features, tumor budding, lymphovascular invasion, tumor grading, and micro staging repeatedly resulted to be significantly associated with nodal involvement: currently, in the presence of even one of these morphological features, surgical resection is proposed, thus favoring lymph node metastases identification but also increasing the percentages of cases submitted to surgery with no lymph node involvement $(7,18)$.

Based on this observation, a significant subgroup of patients is overtreated $(19,20)$. In these cases, colectomy with lymphadenectomy is stadiative rather than curative, and it exposes patients to surgery-related morbidity and mortality risks that could be avoided through improved patient selection. Improvement of the risk estimation of nodal metastasis in this setting is an unmet clinical need and would help avoid these risks. In particular, it has to be considered that most of the patients without evidence of node metastasis after surgery were surgically treated because of the presence of a single high-risk parameter, thus novel approaches should focus on developing combined multiparametric scores $(7,8,18,21)$.

Fostered by this state of the art, this study aims to improve pT1 CRC risk stratification by proposing a novel and effective clinicopathological predictor score of nodal metastases, established through the analysis of a comprehensive range of clinical and histopathological features in a large consecutive series of pT1 CRC, surgically treated at a tertiary referral institution.

\section{MATERIALS AND METHODS}

\section{Dataset Construction}

This is a retrospective study based on a consecutive series of surgically resected pT1 CRC samples (colectomy plus lymphadenectomy) collected from the pathology archives of the "Città della Salute e della Scienza" University Hospital in Turin and diagnosed from January 2010 to March 2019. Demographic, clinical, and histopathological data were extracted from the diagnostic reports, and then pseudo-anonymized by a Unit member not involved in the study. Cases receiving neoadjuvant treatment (i.e., chemoradiotherapy) or lacking material for histological revision were excluded. A final series of 207 samples were collected.

Our study was based on the assessment of hematoxylineosin (H\&E) slides only as per routine practice at our institution. Original $\mathrm{H} \& \mathrm{E}$ slides were retrieved and then independently reviewed by three pathologists (AG, LB, and PC). Disagreements were discussed and jointly resolved by consensus.
Histopathological features were assessed and scored according to published studies and international guidelines (Figure 1).

In particular, a tumor "bud" was defined as a cluster of less than five cells located at the invasive front of the tumor (2224). Based on the clusters quantity, tumor budding was further stratified into a low (less than five clusters per hotspot in a field measuring $0.785 \mathrm{~mm}^{2}$ ) and high grade (equal or more than five clusters per hotspot in a field measuring $0.785 \mathrm{~mm}^{2}$ ) according to a binary system as reported in the literature $(8,22,25,26)$.

Lymphovascular invasion was reported whether tumor cells were identified within endothelial-outlined peritumoral stromal vessels (24). Tumor differentiation grade was attributed according to the least differentiated tumoral component (24). The depth and width of submucosal invasion were assessed and analyzed using 1 and $4 \mathrm{~mm}$ cutoff values, respectively (27-29).

Regarding the tumor-infiltrating lymphocytes (TILs) assessment, standardized international definition criteria are currently lacking, particularly in the pT1 CRC setting. Therefore, we graded TILs with a semi-quantitative three-tier approach, evaluating the quantity and location of lymphocytes. In particular, we considered only TILs outlining tumor cells at the invasive tumor front, whereas TILs/lymphocytes interspersed within the tumor bulk and/or located in superficial tumor layers were neglected to avoid potential confounders related to luminal/mechanic injury and tumor superficial erosion/necrosis. Then, cases with no peritumoral lymphocytes were reported as "absent TILs," whereas "high TILs" were cases with lymphocytes continuously outlining tumor cells at the tumor invasive front and extending in the Surrounding stroma. "Mild TILs" referred to all the cases with intermediate features (interrupted outlining and/or infiltrate limited to tumor cells surrounding area) (Figure 2).

The clinical and histopathological features evaluated in this study are reported in Table $\mathbf{1}$, whereas the overall study design is represented in Figure 3.

\section{Statistical Analysis}

Statistical analyses were performed with the Stata 15.0 statistical software (StataCorp, College Station, TX, USA.), applying proper tests for categorical (Pearson's Chi-squared - $\chi 2$ - test) and numerical variables ( $\mathrm{T}$ Student's test, Wilcoxon signed-rank test). Bonferroni correction was performed for multiple groups correlations. Univariate binary logistic regression analyses were performed to assess the correlation between the lymph node metastatic status and other variables, calculating relative Odds Ratio (OR) and 95\% CI. Statistical analyses were considered significant according to the standard $p$-value $<0.05$.

\section{RESULTS}

\section{Clinical and Histopathological Features}

Our population presented a median age of 70 years (interval: $37-90)$ and was mainly composed of female patients (114 cases; $55.1 \%)$. Most of the collected lesions were non-pedunculated polyps (177 cases; $85.5 \%)$, sited in the sigmoid-rectal tract (113 cases; $54.6 \%$ ), and 46 specifically located in the rectum (22.2\%), without synchronous polyps elsewhere (165 cases; 79.7\%). Most 

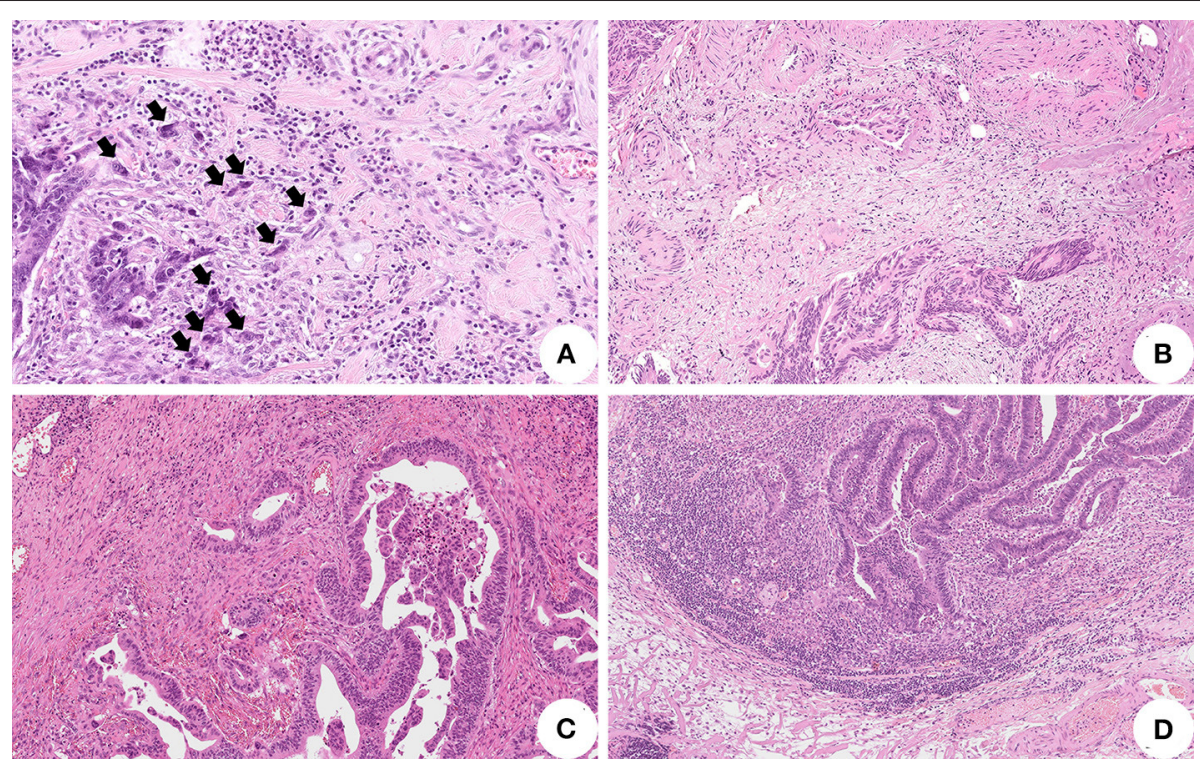

FIGURE 1 | Histopathological features associated with lymph node metastasis in pT1 colorectal cancer (CRC). (A) High-grade tumor budding represented by equal or more than five clusters of less than five tumor cells at the invasive front of the tumor (black arrows) (original magnification: 200X); (B) Tumor cells invasion of peritumoral stromal vessels representing lymphovascular invasion (original magnification: 100X); (C) Absent/mild tumor-infiltrating lymphocytes surrounding tumor cells (original magnification: 100X); (D) High tumor-infiltrating lymphocytes facing the invasive tumor front (original magnification: 100X).
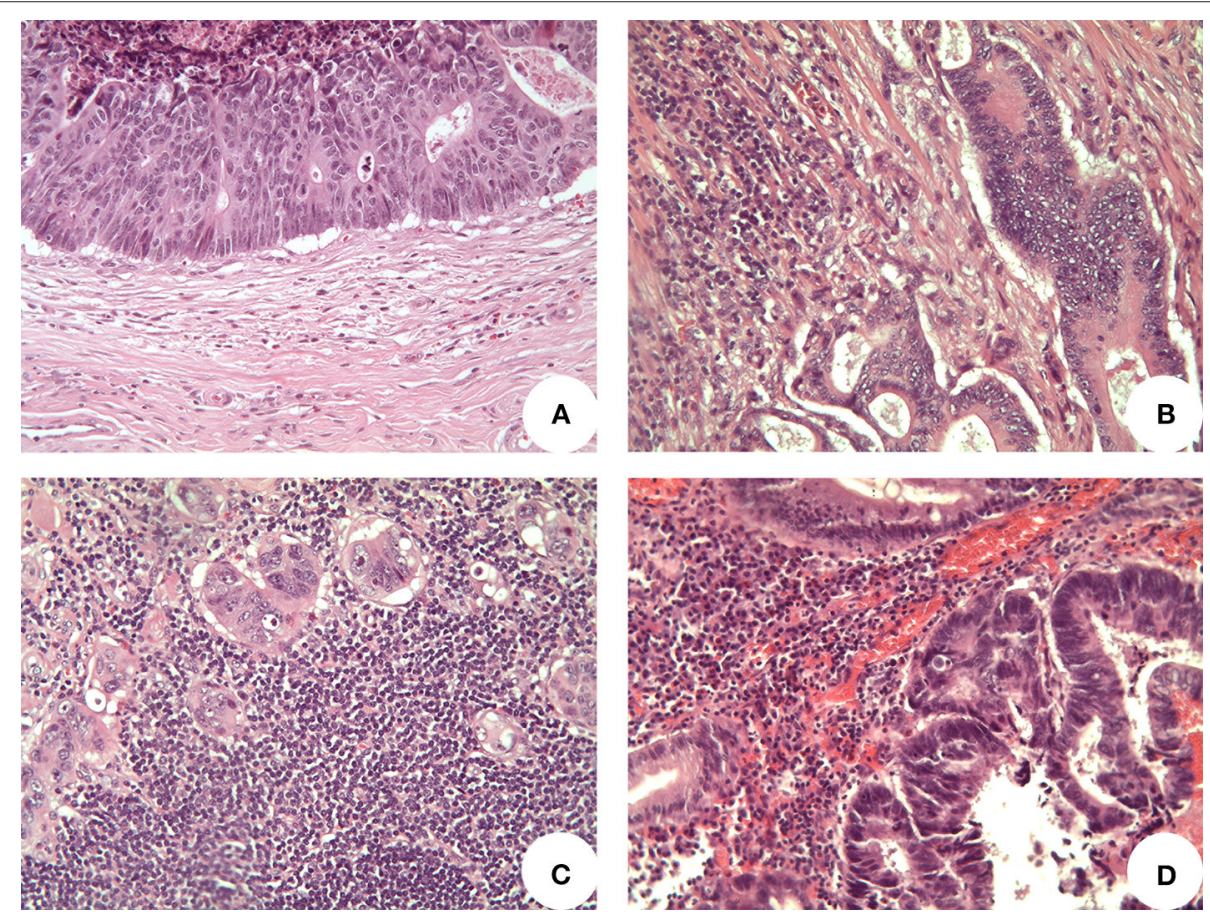

FIGURE 2 | Representative images of tumor infiltrating lymphocytes (TILs) (original magnification 200x). (A) "Absent TILs" cases presented no lymphocytes at the invasive front of tumor; (B) "mild TILs" cases showed scattering lymphocytes partially surrounding tumor cells; (C) "high TILs" cases presented several lymphocytes continuously outlining tumor cells at the invasive tumor front and extending in the surrounding stroma; (D) lymphocytes located in superficial tumor layers were not considered, as well as lymphocytes within the tumor bulk.

cases presented an infiltrative growth pattern (134 cases; 64.7\%) and were graded as moderately differentiated (G2) (169 cases; $81.6 \%$ ), while mucinous features were frequently absent (173 cases; 83.6\%). TILs were mild in most cases (165 cases; 79.7\%), while high-grade tumor budding and lymphovascular invasion were observed in a minority ( 8.7 and $3.9 \%$, respectively) of cases. 
TABLE 1 | Clinical and histopathological variables evaluated in our study.

\begin{tabular}{|c|c|c|c|}
\hline \multicolumn{2}{|c|}{ Characteristic } & \multirow{2}{*}{$\begin{array}{c}\begin{array}{c}\text { Total } \\
(\boldsymbol{n}=\mathbf{2 0 7})\end{array} \\
93\end{array}$} & \multirow{2}{*}{$\begin{array}{c}\begin{array}{c}\text { Percentage } \\
\text { (\%) }\end{array} \\
44.9\end{array}$} \\
\hline Gender & Male & & \\
\hline & Female & 114 & 55.1 \\
\hline Age & Median (interval) & $70(37-90)$ & - \\
\hline \multirow[t]{2}{*}{ Age } & $<65$ & 66 & 31.9 \\
\hline & $\geq 65$ & 141 & 68.1 \\
\hline \multirow[t]{2}{*}{ Morphology } & Non pedunculated & 177 & 85.5 \\
\hline & Pedunculated & 30 & 14.5 \\
\hline \multirow[t]{6}{*}{ Site } & Cecum-Right & 69 & 33.3 \\
\hline & Transverse & 14 & 6.8 \\
\hline & Left & 11 & 5.3 \\
\hline & Sigmoid-rectum & 113 & 54.6 \\
\hline & Sigmoid & 67 & 32.4 \\
\hline & Rectum & 46 & 22.2 \\
\hline \multirow[t]{2}{*}{ Simultaneous polyps } & Absent & 165 & 79.7 \\
\hline & Present & 42 & 20.3 \\
\hline \multirow[t]{3}{*}{ Grade } & Well differentiated (G1) & 31 & 15.0 \\
\hline & $\begin{array}{l}\text { Moderately } \\
\text { differentiated (G2) }\end{array}$ & 169 & 81.6 \\
\hline & $\begin{array}{l}\text { Poorly differentiated } \\
\text { (G3) }\end{array}$ & 7 & 3.4 \\
\hline \multirow[t]{2}{*}{ Mucinous feature } & Absent & 173 & 83.6 \\
\hline & Present & 34 & 16.4 \\
\hline Lymphovascular & Absent & 199 & 96.1 \\
\hline invasion & Present & 8 & 3.9 \\
\hline \multirow[t]{3}{*}{ TILs } & Absent & 24 & 11.6 \\
\hline & Mild & 165 & 79.7 \\
\hline & High & 18 & 8.7 \\
\hline \multirow[t]{2}{*}{ Tumor budding } & Low-grade & 189 & 91.3 \\
\hline & High-grade & 18 & 8.7 \\
\hline \multirow[t]{2}{*}{ Sampled lymph nodes } & $<12$ & 88 & 42.5 \\
\hline & $\geq 12$ & 119 & 57.5 \\
\hline Lymph nodes & Absent & 189 & 91.3 \\
\hline metastasis & Present & 18 & 8.7 \\
\hline \multirow[t]{2}{*}{ Growth pattern } & Expansive & 73 & 35.3 \\
\hline & Infiltrative & 134 & 64.7 \\
\hline \multirow[t]{2}{*}{ Depth of invasion } & $<1 \mathrm{~mm}$ & 22 & 10.6 \\
\hline & $\geq 1 \mathrm{~mm}$ & 185 & 89.4 \\
\hline \multirow[t]{2}{*}{ Width of invasion } & $<4 \mathrm{~mm}$ & 44 & 21.3 \\
\hline & $\geq 4 \mathrm{~mm}$ & 163 & 78.7 \\
\hline
\end{tabular}

With regards to the Ueno's method for pT1 micro-staging (28), most of the lesions presented a depth of invasion $\geq 1 \mathrm{~mm}(185$ cases; $89.4 \%$ ) and a width of invasion $\geq 4 \mathrm{~mm}$ (163 cases; $78.7 \%$ ). All clinical and histopathological data are reported in Table 1.

\section{Lymph Node Metastasis: Defining "That" pT1 Profile}

We analyzed the association between all the assessed variables and lymph node involvement to build our predictive risk score.
We registered 18 cases with lymph node metastasis (8.7\%). In this population, we observed that nodal involvement was correlated with younger age (cut-off: 65 years) $(p=$ $0.005)$, presence of lymphovascular invasion $(p<0.001)$, absent/mild TILs $(p=0.006)$, and high-grade tumor budding $(p=0.003)$ (Table 2).

The univariate logistic regression confirmed these data, revealing that lymphovascular invasion (OR: 23.8; CI: 5.12110.9 ) and high-grade tumor budding (OR: 5.21; CI: 1.60-16.8) were significantly associated with an increased risk of nodal metastasis, while age at diagnosis $>65$ years (OR: 0.26 ; CI: $0.09-$ 0.71 ) and high TILs (OR: 0.19; CI: 0.06-0.59) showed a protective effect (Table 3).

Fostered by the increasing evidence supporting both tumor budding relevance in pT1 CRC risk assessment and its relationship with lymphovascular invasion, we decided to stratify our population according to this parameter to verify its significance in our series. We compared samples with lowgrade (189 cases; $91.3 \%)$ and high-grade (18 cases; $8.7 \%)$ tumor budding observing that high-grade tumor budding strongly correlated with lymph node metastasis $(p=0.003)$ and with lymphovascular invasion $(p<0.001)$, as well. In addition, the univariate logistic regression confirmed that lymphovascular invasion (OR: 13.21; CI: 2.98-58.55) was significantly correlated with high-grade tumor budding.

Finally, we also analyzed the role of tumor grade, another variable routinely used to predict lymph nodes metastasis (7), but we did not identify any correlation with lymph node metastasis $(p=0.456)$.

Since our consecutive series included also 88 cases with $<12$ sampled lymph nodes and considering the higher risk of recurrence and understanding associated with this sampling, we decided to perform the same analysis excluding non-metastatic cases (N0) with $<12$ lymph nodes $(\mathrm{n}=79)$ and performed our analysis in the resulting series [thus composed of metastatic cases $(\mathrm{N}+)$ and non-metastatic cases (N0) with $>12$ lymph nodes $(\mathrm{n}=128)]$. In this subgroup, we observed the same significant correlations between nodal involvement and clinical-pathologic variables [younger age $(p=0.006)$, presence of lymphovascular invasion $(p<0.001)$, absent/mild TILs $(p=0.006)$, and highgrade tumor budding $(p=0.008)]$, confirmed by univariate logistic regression [lymphovascular invasion (OR: 20.7; CI: 3.65118.1 ) and high-grade tumor budding (OR: 4.90; CI: 1.39-17.2) associated with an increased risk of nodal metastasis; age at diagnosis $>65$ years (OR: 0.24 ; CI: $0.09-0.70$ ) and high TILs (OR: 0.16 ; CI: 0.05-0.49) associated with a protective effect].

\section{Prediction of Lymph Node Metastasis: Assembling the Combined Score}

Based on these results, we combined the features significantly related to lymph node metastasis (i.e., age at diagnosis, tumor budding, lymphovascular invasion, and TILs) to build our clinico-histopathological metastatic risk score.

We conferred at one point that any of the following features were present: age at diagnosis <65-year, high-grade tumor budding, presence of lymphovascular invasion, and absent/mild 


\section{The importance of being "that" colorectal pT1 \\ A combined clinico-pathological predictive score to improve nodal risk stratification}

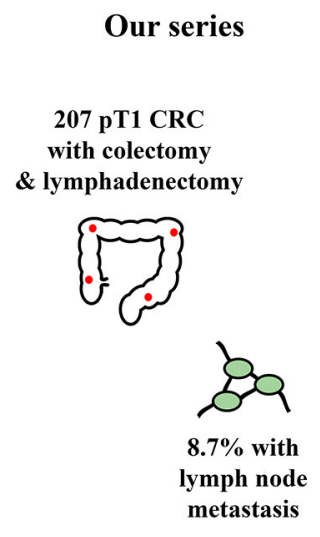

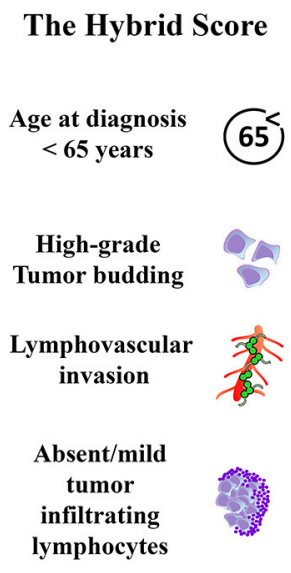

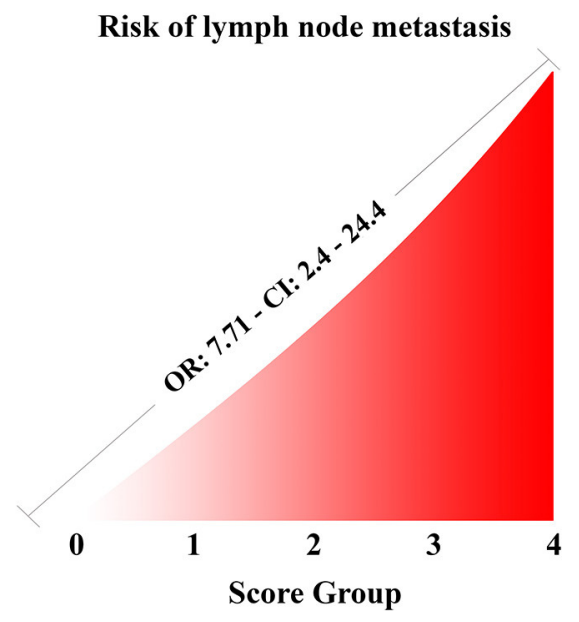

FIGURE 3 | Graphical representation of our study.

TILs. Therefore, the score would define five possible subgroups ranging from Score 0 (no variables) to Score 4 (all variables simultaneously present).

Applying the score to the whole population, scores 1 and 2 were the most represented groups (121 cases and 63 cases, respectively). Nodal metastasis significantly correlated with our score stratification $(p<0.001)$ and, of note, no metastatic cases were observed in the score 0 groups $(n=13)$, whereas all score 4 cases $(n=2)$ presented lymph node metastasis (Table 4).

In addition, the correlation $(p<0.001)$ was maintained even when comparing cases with a score $\geq 2$ and cases with a score of 0 or 1 (Table 5 ).

Univariate logistic regression also confirmed the correlation between these two clusters: score $\geq 2$ cases presented a significantly higher risk of nodal metastasis compared to score 0 and 1 cases (OR: 7.71; CI: 2.4-24.4) (Table 6).

These analyses were also performed in the previously described subgroup $[\mathrm{N}+$ and $\mathrm{N} 0$ with $>12$ lymph nodes $(\mathrm{n}=128)$ ], showing similar outcomes either considering the scoring groups separately (Table 7 ) or clustered in score $0 / 1$ vs. score $\geq 2$ (Table 7 ), the latter confirmed by univariate logistic regression (Table 8 ).

\section{DISCUSSION}

This study aimed to enhance the clinical management of endoscopically resected pT1 CRC by identifying and combining metastasis-correlated clinicopathological features in a predictive score of nodal metastasis.
Our series of retrospective consecutive pT1 CRC presented a percentage of nodal metastasis $(8,7 \%)$ in agreement with the literature range of $4.9-16.9 \%(7,8,19,21)$. This data shows that, to date, a large number of cases are potentially overtreated and exposed to significant surgical-related risks without certain benefits except for achieving definitive pathological tumor staging.

Until now, the prediction of CRC pT1 nodal status has been based on histopathological features alone assessed on endoscopically-resected specimens. According to the current international guidelines, the presence of even one single histopathological parameter among poorly differentiated tumors (G3), high-grade tumor budding, lymphovascular invasion, and submucosal invasion $\geq 1 \mathrm{~mm}$ depth or $\geq 4 \mathrm{~mm}$ width is routinely used to assign a high risk of node metastasis, aiming for identifying any potential metastatic case but leading to the surgical overtreatment of patients with no metastatic disease (11, 13, 28-33). Of note, these features proved to correlate with node metastasis although a somewhat disappointing interobserver agreement $(34,35)$. In our study, we confirmed lymphovascular invasion and high-grade tumor budding, and additionally identified absent/mild TILs and younger age (cut-off: 65 years) as relevant features related to nodal involvement and, therefore, we combined them to build our risk score.

Among these, tumor budding and lymphovascular invasion have been thoroughly studied and their association with nodal metastasis is well recognized $(8,18,33,36)$. Recent evidence also suggested that these features are intertwined and could represent two sides of the same coin, ultimately leading to lymph node metastasis (21) since cells composing the tumor "buds" were 
TABLE 2 | Distribution of clinical data and pathological features based on lymph nodes metastasis.

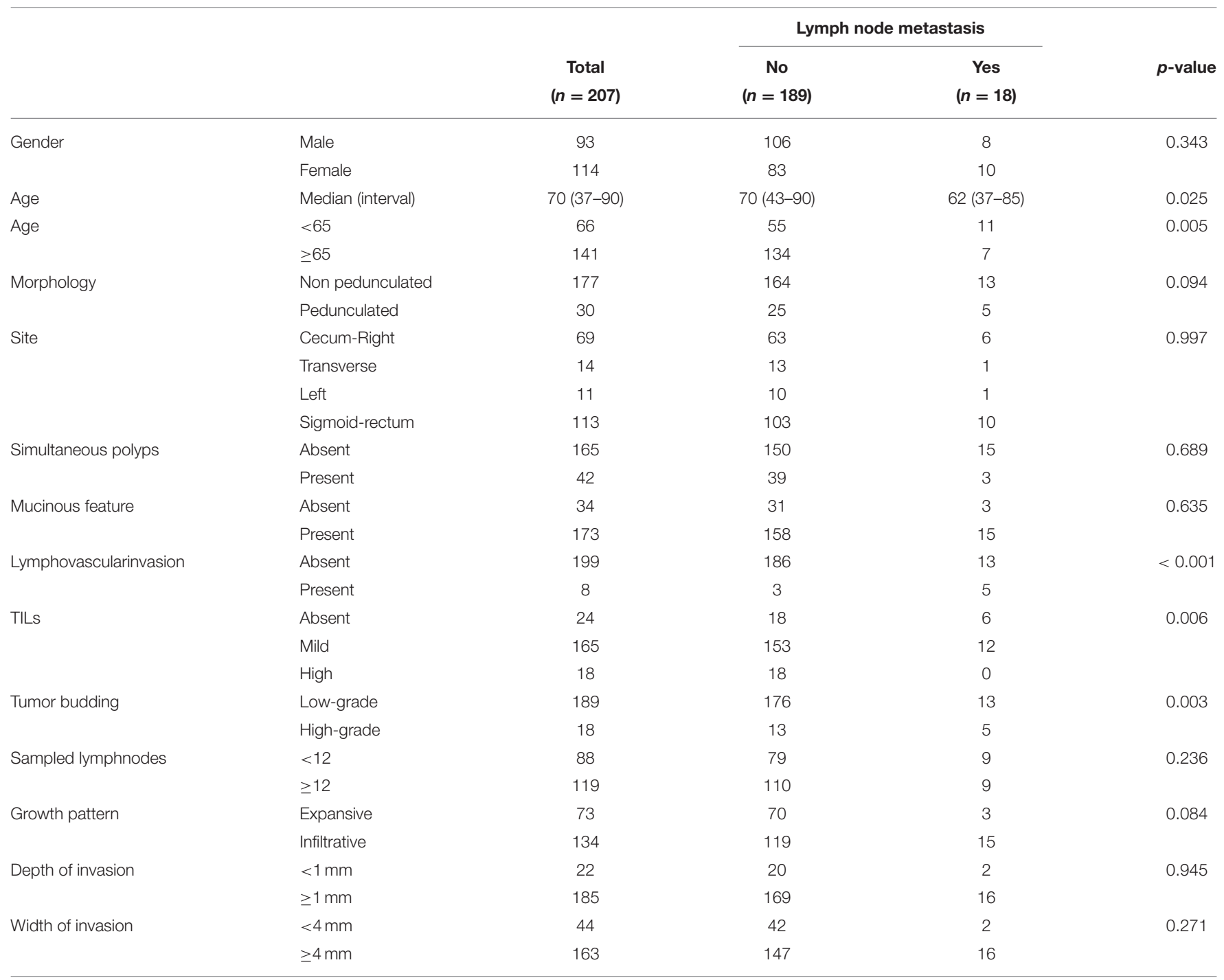

TABLE 3 | Univariate logistic regression analysis between clinico-pathological variables and lymph nodes metastasis.

\begin{tabular}{lccc}
\hline & OR & CI & p-value \\
\hline Gender (Male vs. Female) & 1.59 & $0.60-4.22$ & 0.346 \\
Age (linear) & 0.93 & $0.88-0.97$ & 0.003 \\
Age (>65-year-old) & 0.26 & $0.09-0.71$ & 0.008 \\
Lymphovascular invasion & 23.8 & $5.12-110.9$ & $<0.001$ \\
High-grade tumor budding & 5.21 & $1.60-16.8$ & 0.006 \\
High TILs & 0.19 & $0.06-0.59$ & 0.004 \\
Pedunculated morphology & 2.52 & $0.82-7.68$ & 0.103 \\
Grading & 2.28 & $0.63-8.29$ & 0.210 \\
Sampled lymph nodes $>12$ & 0.72 & $0.27-1.89$ & 0.503 \\
Sigmoid-rectum site & 1.04 & $0.39-2.76$ & 0.931 \\
\hline
\end{tabular}

found to be also responsible for the invasion of nearby stromal lymphovascular vessels. These cells exhibited epithelial and
TABLE 4 | Correlation analysis between the score group and presence of lymph node metastasis.

\begin{tabular}{|c|c|c|c|}
\hline \multirow[t]{2}{*}{ Score group } & \multicolumn{2}{|c|}{ Lymph node metastasis } & \multirow[t]{2}{*}{$p$-value } \\
\hline & No & Yes & \\
\hline 0 & 13 & 0 & $<0.001$ \\
\hline 1 & 117 & 4 & \\
\hline 2 & 54 & 9 & \\
\hline 3 & 5 & 3 & \\
\hline 4 & 0 & 2 & \\
\hline
\end{tabular}

mesenchymal markers suggesting the activation of the epithelialmesenchymal transition process, an aggressive tumor phenotype associated with poor survival and resistance to therapy (37-41). Our data support their strong reciprocal intertwining and their influence on lymph nodes metastasis development. 
TABLE 5 | Correlation analysis clustering cases with score $<2$ vs. score $\geq 2$.

\begin{tabular}{|c|c|c|c|}
\hline \multirow[t]{2}{*}{ Score group } & \multicolumn{2}{|c|}{ Lymph node metastasis } & \multirow[t]{2}{*}{$p$-value } \\
\hline & No & Yes & \\
\hline $0-1$ & 130 & 4 & $<0.001$ \\
\hline $2-4$ & 59 & 14 & \\
\hline
\end{tabular}

TABLE 6 | Univariate logistic regression evaluating our score outcomes predicting lymph node metastasis.

\begin{tabular}{lllll}
\hline & & OR & CI & p-value \\
\hline $\begin{array}{l}\text { Score group } \\
\text { (clustered score) }\end{array}$ & Score 2-4 vs. score 0-1 & 7.71 & $2.4-24.4$ & 0.001 \\
\hline
\end{tabular}

TABLE 7 | Correlation analysis between the score groups and presence of lymph nodes metastasis in the $\mathrm{N}+$ plus $\mathrm{NO}$ with $>12$ lymph nodes subgroup.

\begin{tabular}{lccc}
\hline Score group & \multicolumn{2}{c}{ Lymph node metastasis } & p-value \\
\cline { 2 - 3 } & No & Yes & \\
\hline 0 & 7 & 0 & $<0.001$ \\
1 & 71 & 4 & \\
2 & 29 & 9 & \\
3 & 3 & 3 & \\
4 & 0 & 2 & $<0.001$ \\
$0-1$ & 78 & 4 & \\
$2-4$ & 32 & 14 & \\
\hline
\end{tabular}

TABLE 8 | Univariate logistic regression evaluating the association between the score groups and lymph node metastasis in the N+ plus NO with $>12$ lymph nodes cases.

\begin{tabular}{lllll}
\hline & & OR & Cl & p-value \\
\hline $\begin{array}{l}\text { Score group } \\
\text { (clustered score) }\end{array}$ & Score 2-4 vs. score 0-1 & 8,2 & $2.5-26.7$ & 0.001 \\
\hline
\end{tabular}

Our results also demonstrate that TILs are significantly correlated with the risk of harboring a nodal metastasis, a finding in agreement with the established role of the immune system in influencing CRC growth and survival (42-45). However, it should be noted that so far, studies evaluating the role of TILs in CRC mainly focused on advanced disease settings. The few reports addressing pT1 CRC provided conflicting results. (43, 44, 46-48). A univariate analysis of 102 endoscopically resected pT1 CRCs reported an increased number of CD3 positive TILs in the metastatic group, but this finding was not confirmed by multivariate analysis (21). No correlations were observed analyzing the CD8 positive TILs (21). Differently, a recent study by Kang et al. analyzed the distribution and mean numbers of CD3, CD8, and FOXP3 positive lymphocytes in pT1 CRC and identified a significant association between lymph node metastasis and a lower number of CD8 positive lymphocytes located within the tumor core (49). In the present study, we demonstrated a correlation between absent/mild TILs and a higher risk of nodal involvement. This association seems to be particularly relevant since none of our cases with high TILs presented nodal metastasis, while the four score 1 cases presenting nodal metastasis received this score exactly due to the presence of absent/mild TILs. We believe that TILs could become a significant histopathological feature of pT1 CRC, representing a morphological counterpart of tumor immunobiology and immune system activation against tumor growth. In this regard, our results support the relevance of this parameter in shaping tumor invasiveness even at early disease stages, but further studies should specifically investigate TILs in early CRC to confirm their predictive significance in terms of nodal metastasis and provide additional insights on their mechanistic role and develop specific guidelines regarding their assessment.

Lastly, the predictive significance of age at diagnosis is of particular interest since it shows the importance of clinical variables even in this early oncological setting. Moreover, whereas the assessment of histopathological features alone can be hampered by inter-observer variability (50), age at diagnosis is not. Younger age is also known to be related to more aggressive CRC lesions (51-54).

We did not confirm micro staging ( $\geq 1 \mathrm{~mm}$ depth and $\geq 4 \mathrm{~mm}$ width of invasion) nor tumor grading as potential risk factors of nodal involvement. Similar evidence has been recently reported in the literature: in particular, micro staging reliability in pT1 CRC has been questioned for the significant influence of technical processing and lesion morphology on its interpretation; similarly, the importance of tumor grading as a predictive marker has been found to be overall limited compared with other morphological features (55-59).

In the practical daily routine, some $\mathrm{pT} 1 \mathrm{CRC}$ cases, although close to the recommended cut-off, did not meet the required number of harvested lymph nodes. Indeed, this is a limitation that actually occurs, potentially impacting the pT1 CRC staging $(60,61)$. Aiming to develop a score that can be applied in a "realworld" pT1 CRC series, we preferred to also maintain these cases and test our score in both scenarios, thus considering either all cases (including the ones with $<12$ lymph nodes) or the subgroup of $\mathrm{N}+$ and $\mathrm{N} 0>12$ only cases. Indeed, our score maintains the same level of statistic and clinical significance, further confirming its practical relevance.

We acknowledge that our study presents some potential limitations, including its retrospective nature and the limited, although considerable, sample size. Moreover, future studies should investigate the efficacy of the here proposed approach on endoscopic resection samples.

Ultimately, our score improves the overall identification of patients who would benefit from a surgical approach following endoscopically resected pT1 CRC compared to the evidence reported so far in the literature (62-64). It should also be noted that balancing the risks due to over-and undertreatment is extremely challenging when dealing with an early tumor stage. Identifying subgroups of patients, no matter how small, with very low or very high metastatic risks is particularly important since it allows to confidently propose a therapeutic option to these patients. Our score enabled this result since no score 0 patient 
showed nodal metastasis, while all score 4 had metastatic disease. Although the sample sizes of these groups were particularly limited, these promising results warrant further validation. Among patients with intermediate-risk scores (score 1-3), we observed a progressive increase of nodal metastasis (score 1: $3.4 \%$, score $2: 16.7 \%$, score $3: 60.0 \%$ ), a piece of information that would not have been available by employing the conventional dichotomized approach. This stratified risk assessment could help tailor patients' management by multidisciplinary boards.

In conclusion, despite some limitations, including the retrospective and single-institutional nature, our study allowed us to develop a novel multiparametric score combining evidencebased histopathological features with age at diagnosis as a clinical variable. Our score represents an effective system to estimate the lymph node metastasis risk, superior to the current single parameter-based risk assessment. Further multicentric and ideally prospective studies are recommended to confirm our findings and enable the adoption of the proposed score within multidisciplinary CRC tumor boards to guide patients' management.

\section{DATA AVAILABILITY STATEMENT}

The raw data supporting the conclusions of this article will be made available by the authors, without undue reservation.

\section{REFERENCES}

1. Collaborators GBDCC. The global, regional, and national burden of colorectal cancer and its attributable risk factors in 195 countries and territories, 1990-2017: a systematic analysis for the Global Burden of Disease Study 2017. Lancet Gastroenterol Hepatol. (2019) 4:91333. doi: 10.1016/S2468-1253(19)30345-0

2. Amri R, Bordeianou LG, Sylla P, Berger DL. Impact of screening colonoscopy on outcomes in colon cancer surgery. JAMA Surg. (2013) 148:74754. doi: 10.1001/jamasurg.2013.8

3. Gupta N, Kupfer SS, Davis AM. Colorectal cancer screening. JAMA. (2019) 321:2022-3. doi: 10.1001/jama.2019.4842

4. Kahi CJ, Imperiale TF, Juliar BE, Rex DK. Effect of screening colonoscopy on colorectal cancer incidence and mortality. Clin Gastroenterol Hepatol. (2009) 7:770-5. doi: 10.1016/j.cgh.2008.12.030

5. Kahi CJ, Anderson JC, Rex DK. Screening and surveillance for colorectal cancer: state of the art. Gastrointest Endosc. (2013) 77:335-50. doi: 10.1016/j.gie.2013.01.002

6. Brierley JG, M.; Wittekind, C. TNM classification of malignant tumors. Eighth ed: John Wiley \& Sons, Ltd. (2017).

7. Bosch SL, Teerenstra S, de Wilt JH, Cunningham C, Nagtegaal ID. Predicting lymph node metastasis in pT1 colorectal cancer: a systematic review of risk factors providing rationale for therapy decisions. Endoscopy. (2013) 45:82734. doi: 10.1055/s-0033-1344238

8. Cappellesso R, Luchini C, Veronese N, Lo Mele M, Rosa-Rizzotto E, Guido E, et al. Tumor budding as a risk factor for nodal metastasis in pT1 colorectal cancers: a meta-analysis. Hum Pathol. (2017) 65:6270. doi: 10.1016/j.humpath.2017.04.013

9. Bianco F, Arezzo A, Agresta F, Coco C, Faletti R, Krivocapic Z, et al. Practice parameters for early colon cancer management: Italian society of colorectal surgery (societa Italiana di chirurgia colo-rettale; SICCR) guidelines. Tech Coloproctol. (2015) 19:577-85. doi: 10.1007/s10151-015-1361-y

10. Kim JB, Lee HS, Lee HJ, Kim J, Yang DH, Yu CS, et al. Long-term outcomes of endoscopic vs. surgical resection of superficial submucosal colorectal cancer. Dig Dis Sci. (2015) 60:2785-92. doi: 10.1007/s10620-015-3530-2

\section{ETHICS STATEMENT}

The studies involving human participants were reviewed and approved by the Institutional Review Board (or Ethics Committee) of the University of Turin (approval number: DSM-ChBU $n^{\circ}$ 03/2020, approved in October 2020). Written informed consent for participation was not required for this study in accordance with the national legislation and the institutional requirements.

\section{AUTHOR CONTRIBUTIONS}

LB and PC: conceptualization and funding acquisition. AG, EF, GB, SO-A, RS, IC, LB, and PC: methodology and writingreview and editing. AG, EF, GB, SO-A, and LB: formal analysis. AG and EF: writing-original draft preparation. All authors contributed to the article and approved the submitted version.

\section{FUNDING}

This research was funded by the Rete Oncologica del Piemonte e della Valle d'Aosta (Oncology Network of Piedmont and Aosta Valley-Italy; Grant to LB and PC, no specific grant number available).

11. Steele RJ, Pox C, Kuipers EJ, Minoli G, Lambert R, International Agency for Research on C. European guidelines for quality assurance in colorectal cancer screening and diagnosis. Endoscopy. (2012) 44:SE14050. doi: 10.1055/s-0032-1309802

12. Quirke P, Risio M, Lambert $R$, von Karsa L, Vieth $M$, International Agency for Research on C. European guidelines for quality assurance in colorectal cancer screening and diagnosis. Endoscopy. (2012) 44:SE11630. doi: 10.1055/s-0032-1309797

13. Labianca R, Nordlinger B, Beretta GD, Mosconi S, Mandala M, Cervantes A, et al. Early colon cancer: ESMO Clinical Practice Guidelines for diagnosis, treatment and follow-up. Ann Oncol. (2013) 24:vi64-72. doi: 10.1093/annonc/mdt354

14. Hassan C, Wysocki PT, Fuccio L, Seufferlein T, Dinis-Ribeiro M, Brandao $\mathrm{C}$, et al. Endoscopic surveillance after surgical or endoscopic resection for colorectal cancer: European Society of Gastrointestinal Endoscopy (ESGE) and European Society of Digestive Oncology (ESDO) Guideline. Endoscopy. (2019) 51:266-77. doi: 10.1055/a-0831-2522

15. Hassan C, Antonelli G, Dumonceau JM, Regula J, Bretthauer M, Chaussade S, et al. Post-polypectomy colonoscopy surveillance: European Society of Gastrointestinal Endoscopy (ESGE) Guideline - Update 2020. Endoscopy. (2020) 52:687-700. doi: 10.1055/a-1185-3109

16. Ikematsu H, Yoda Y, Matsuda T, Yamaguchi Y, Hotta K, Kobayashi N, et al. Long-term outcomes after resection for submucosal invasive colorectal cancers. Gastroenterology. (2013) 144:551-9. doi: 10.1053/j.gastro.2012. 12.003

17. Hohenberger W, Weber K, Matzel K, Papadopoulos T, Merkel S. Standardized surgery for colonic cancer: complete mesocolic excision and central ligationtechnical notes and outcome. Colorectal Dis. (2009) 11:354-64; discussion 64-5. doi: 10.1111/j.1463-1318.2008.01735.x

18. Zhang Q, Wang L, Huang $\mathrm{D}, \mathrm{Xu} \mathrm{M}$, Weng $\mathrm{W}$, $\mathrm{Ni} \mathrm{S}$, et al. Pathological risk factors for lymph node metastasis in patients with submucosal invasive colorectal carcinoma. Cancer Manag Res. (2019) 11:1107-14. doi: 10.2147/CMAR.S181740

19. Senore C, Giovo I, Ribaldone DG, Ciancio A, Cassoni P, Arrigoni A, et al. Management of Pt1 tumors removed by endoscopy during colorectal cancer 
screening: outcome and treatment quality indicators. Eur J Surg Oncol. (2018) 44:1873-9. doi: 10.1016/j.ejso.2018.09.009

20. Backes Y, Elias SG, Groen JN, Schwartz MP, Wolfhagen FHJ, Geesing JMJ, et al. Histologic factors associated with need for surgery in patients with pedunculated T1 colorectal carcinomas. Gastroenterology. (2018) 154:164759. doi: 10.1053/j.gastro.2018.01.023

21. Cappellesso R, Nicole L, Zanco F, Lo Mele M, Fassina A, Ventura $\mathrm{L}$, et al. Synchronous nodal metastatic risk in screening detected and endoscopically removed pT1 colorectal cancers. Pathol Res Pract. (2020) 216:152966. doi: 10.1016/j.prp.2020.152966

22. Ueno H, Murphy J, Jass JR, Mochizuki H, Talbot IC. Tumor 'budding' as an index to estimate the potential of aggressiveness in rectal cancer. Histopathology. (2002) 40:127-32. doi: 10.1046/j.1365-2559.2002.01324.x

23. Lugli A, Kirsch R, Ajioka Y, Bosman F, Cathomas G, Dawson H, et al. Recommendations for reporting tumor budding in colorectal cancer based on the international tumor budding consensus conference (ITBCC) 2016. Mod Pathol. (2017) 30:1299-311. doi: 10.1038/modpathol.2017.46

24. Nagtegaal ID, Odze RD, Klimstra D, Paradis V, Rugge M, Schirmacher P, et al. The 2019 WHO classification of tumors of the digestive system. Histopathology. (2020) 76:182-8. doi: 10.1111/his.13975

25. Ferlitsch M, Moss A, Hassan C, Bhandari P, Dumonceau JM, Paspatis G, et al. Colorectal polypectomy and endoscopic mucosal resection (EMR): European Society of Gastrointestinal Endoscopy (ESGE) Clinical Guideline. Endoscopy. (2017) 49:270-97. doi: 10.1055/s-0043-102569

26. Trinh A, Ladrach C, Dawson HE, Ten Hoorn S, Kuppen PJK, Reimers MS, et al. Tumor budding is associated with the mesenchymal colon cancer subtype and RAS/RAF mutations: a study of 1320 colorectal cancers with Consensus Molecular Subgroup (CMS) data. Br J Cancer. (2018) 119:124451. doi: 10.1038/s41416-018-0230-7

27. Wang LM, Guy R, Fryer E, Kartsonaki C, Gill P, Hughes C, et al. The Ueno method for substaging pT1 colorectal adenocarcinoma by depth and width measurement: an interobserver study. Colorectal Dis. (2015) 17:67481. doi: 10.1111/codi.12910

28. Ueno H, Mochizuki H, Hashiguchi Y, Shimazaki H, Aida S, Hase K, et al. Risk factors for an adverse outcome in early invasive colorectal carcinoma. Gastroenterology. (2004) 127:385-94. doi: 10.1053/j.gastro.2004.04.022

29. Watanabe T, Itabashi M, Shimada Y, Tanaka S, Ito Y, Ajioka Y, et al. Japanese Society for cancer of the colon and rectum (JSCCR) guidelines 2010 for the treatment of colorectal cancer. Int J Clin Oncol. (2012) 17:129. doi: 10.1007/s10147-011-0315-2

30. Nascimbeni R, Burgart LJ, Nivatvongs S, Larson DR. Risk of lymph node metastasis in T1 carcinoma of the colon and rectum. Dis Colon Rectum. (2002) 45:200-6. doi: 10.1007/s10350-004-6147-7

31. Kitajima K, Fujimori T, Fujii S, Takeda J, Ohkura Y, Kawamata $\mathrm{H}$, et al. Correlations between lymph node metastasis and depth of submucosal invasion in submucosal invasive colorectal carcinoma: a Japanese collaborative study. J Gastroenterol. (2004) 39:534-43. doi: 10.1007/s00535-004-1339-4

32. Kawachi H, Eishi Y, Ueno H, Nemoto T, Fujimori T, Iwashita A, et al. A three-tier classification system based on the depth of submucosal invasion and budding/sprouting can improve the treatment strategy for T1 colorectal cancer: a retrospective multicenter study. Mod Pathol. (2015) 28:872-9. doi: 10.1038/modpathol.2015.36

33. Graham RP, Vierkant RA, Tillmans LS, Wang AH, Laird PW, Weisenberger DJ, et al. Tumor budding in colorectal carcinoma: confirmation of prognostic significance and histologic cutoff in a population-based cohort. Am J Surg Pathol. (2015) 39:1340-6. doi: 10.1097/PAS.0000000000 000504

34. Harris EI, Lewin DN, Wang HL, Lauwers GY, Srivastava A, Shyr Y, et al. Lymphovascular invasion in colorectal cancer: an interobserver variability study. Am J Surg Pathol. (2008) 32:1816-21. doi: 10.1097/PAS.0b013e3181816083

35. Hacking S, Angert M, Jin C, Kline M, Gupta N, Cho M, et al. Tumor budding in colorectal carcinoma: an institutional interobserver reliability and prognostic study of colorectal adenocarcinoma cases. Ann Diagn Pathol. (2019) 43:151420. doi: 10.1016/j.anndiagpath.2019.151420

36. Lee SJ, Kim A, Kim YK, Park WY, Kim HS, Jo HJ, et al. The significance of tumor budding in $\mathrm{T} 1$ colorectal carcinoma: the most reliable predictor of lymph node metastasis especially in endoscopically resected T1 colorectal carcinoma. Hum Pathol. (2018) 78:8-17. doi: 10.1016/j.humpath.2018.02.001

37. Meyer SN, Galvan JA, Zahnd S, Sokol L, Dawson H, Lugli A, et al. Coexpression of cytokeratin and vimentin in colorectal cancer highlights a subset of tumor buds and an atypical cancer-associated stroma. Hum Pathol. (2019) 87:18-27. doi: 10.1016/j.humpath.2019.02.002

38. Zlobec I, Berger MD, Lugli A. Tumor budding and its clinical implications in gastrointestinal cancers. $\mathrm{Br} J$ Cancer. (2020) 123:700-8. doi: 10.1038/s41416-020-0954-z

39. Grigore AD, Jolly MK, Jia D, Farach-Carson MC, Levine H. Tumor budding: the name is EMT. Partial EMT. J Clin Med. (2016) 5(5). doi: $10.3390 / \mathrm{jcm} 5050051$

40. Jager T, Neureiter D, Fallaha M, Schredl P, Kiesslich T, Urbas R, et al. The potential predictive value of tumor budding for neoadjuvant chemoradiotherapy response in locally advanced rectal cancer. Strahlenther Onkol. (2018) 194:991-1006. doi: 10.1007/s00066-018-1340-0

41. Miyata H, Yoshioka A, Yamasaki M, Nushijima Y, Takiguchi S, Fujiwara Y, et al. Tumor budding in tumor invasive front predicts prognosis and survival of patients with esophageal squamous cell carcinomas receiving neoadjuvant chemotherapy. Cancer. (2009) 115:3324-34. doi: 10.1002/cncr.24390

42. Galon J, Costes A, Sanchez-Cabo F, Kirilovsky A, Mlecnik B, LagorcePages C, et al. Type, density, and location of immune cells within human colorectal tumors predict clinical outcome. Science. (2006) 313:19604. doi: $10.1126 /$ science.1129139

43. Narayanan S, Kawaguchi T, Peng X, Qi Q, Liu S, Yan L, et al. Tumor infiltrating lymphocytes and macrophages improve survival in microsatellite unstable colorectal cancer. Sci Rep. (2019) 9:13455. doi: 10.1038/s41598-019-49878-4

44. Xiao B, Peng J, Wang Y, Deng Y, Ou Q, Wu X, et al. Prognostic value of tumor infiltrating lymphocytes combined with PD-L1 expression for patients with solitary colorectal cancer liver metastasis. Ann Transl Med. (2020) 8:1221. doi: 10.21037/atm-20-2762a

45. Liu S, Kong P, Wang X, Yang L, Jiang C, He W, et al. Tumor microenvironment classification based on T-cell infiltration and PD-L1 in patients with mismatch repair-proficient and -deficient colorectal cancer. Oncol Lett. (2019) 17:233543. doi: 10.3892/ol.2018.9826

46. Zhao Y, Ge X, He J, Cheng Y, Wang Z, Wang J, et al. The prognostic value of tumor-infiltrating lymphocytes in colorectal cancer differs by anatomical subsite: a systematic review and meta-analysis. World J Surg Oncol. (2019) 17:85. doi: 10.1186/s12957-019-1621-9

47. Bupathi $\mathrm{M}, \mathrm{Wu} \mathrm{C}$. Biomarkers for immune therapy in colorectal cancer: mismatch-repair deficiency and others. J Gastrointest Oncol. (2016) 7:71320. doi: 10.21037/jgo.2016.07.03

48. Baldin P, Van den Eynde M, Mlecnik B, Galon J. Immunity to live: an immunopathoscore using the consensus Immunoscore to best define the risk of recurrence and death in stage IV metastatic patients. Oncoimmunology. (2020) 9:1826133. doi: 10.1080/2162402X.2020.1826133

49. Kang J, Choi YJ, Kim IK, Lee HS, Kim H, Baik SH, et al. LASSO-based machine learning algorithm for prediction of lymph node metastasis in T1 colorectal cancer. Cancer Res Treat. (2021) 53:773-83. doi: 10.4143/crt.2020.974

50. Gijsbers K, de Graaf W, Moons LMG, Ter Borg F. High practice variation in risk stratification, baseline oncological staging, and follow-up strategies for T1 colorectal cancers in the Netherlands. Endosc Int Open. (2020) 8:E1117E22. doi: 10.1055/a-1192-3545

51. Guo K, Feng Y, Yuan L, Wasan HS, Sun L, Shen M, et al. Risk factors and predictors of lymph nodes metastasis and distant metastasis in newly diagnosed T1 colorectal cancer. Cancer Med. (2020) 9:5095113. doi: $10.1002 / \mathrm{cam} 4.3114$

52. Xu X, Zhang C, Ni X, Wu J, Pan C, Wang S, et al. Population-based analysis on predictors for lymph node metastasis in T1 colon cancer. Surg Endosc. (2020) 34:4030-40. doi: 10.1007/s00464-019-07192-0

53. Meyer JE, Cohen SJ, Ruth KJ, Sigurdson ER, Hall MJ. Young age increases risk of lymph node positivity in early-stage rectal cancer. J Natl Cancer Inst. (2016) 108(1). doi: 10.1093/jnci/djv284

54. Xie X, Yin J, Zhou Z, Dang C, Zhang H, Zhang Y. Young age increases the risk for lymph node metastasis in patients with early colon cancer. BMC Cancer. (2019) 19: 803. doi: 10.1186/s12885-019-5995-4

55. Masaki T, Sugiyama M, Matsuoka H, Abe N, Izumisato Y, Goto A, et al. Clinical utility of grading criteria for submucosal invasion in the 
prognosis of T1 colorectal carcinomas. J Gastroenterol. (2003) 38:3744. doi: 10.1007/s005350300004

56. Rasheed S, Bowley DM, Aziz O, Tekkis PP, Sadat AE, Guenther $\mathrm{T}$, et al. Can depth of tumor invasion predict lymph node positivity in patients undergoing resection for early rectal cancer? a comparative study between t1 and t2 cancers. Colorectal Dis. (2008) 10:231-8. doi: 10.1111/j.1463-1318.2007.01411.x

57. Yim K, Won DD, Lee IK, Oh ST, Jung ES, Lee SH. Novel predictors for lymph node metastasis in submucosal invasive colorectal carcinoma. World J Gastroenterol. (2017) 23:5936-44. doi: 10.3748/wjg.v23.i32. 5936

58. Ueno H, Kajiwara Y, Shimazaki H, Shinto E, Hashiguchi Y, Nakanishi K, et al. New criteria for histologic grading of colorectal cancer. Am J Surg Pathol. (2012) 36:193-201. doi: 10.1097/PAS.0b013e318235edee

59. Shivji S, Conner JR, Barresi V, Kirsch R. Poorly differentiated clusters in colorectal cancer: a current review and implications for future practice. Histopathology. (2020) 77:351-68. doi: 10.1111/his.14128

60. Son SM, Woo CG, Lee OJ, Lee SJ, Lee TG, Lee HC. Factors affecting retrieval of 12 or more lymph nodes in pT1 colorectal cancers. J Int Med Res. (2019) 47:4827-40. doi: 10.1177/0300060519862055

61. Aldecoa I, Montironi C, Planell N, Pellise M, Fernandez-Esparrach G, Gines A, et al. Endoscopic tattooing of early colon carcinoma enhances detection of lymph nodes most prone to harbor tumor burden. Surg Endosc. (2017) 31:723-33. doi: 10.1007/s00464-016-5026-3

62. Yoda Y, Ikematsu H, Matsuda T, Yamaguchi Y, Hotta K, Kobayashi N, et al. A large-scale multicenter study of long-term outcomes after endoscopic resection for submucosal invasive colorectal cancer. Endoscopy. (2013) 45:718-24. doi: 10.1055/s-0033-1344234
63. Asayama N, Oka S, Tanaka S, Nagata S, Furudoi A, Kuwai T, et al. Long-term outcomes after treatment for pedunculated-type T1 colorectal carcinoma: a multicenter retrospective cohort study. J Gastroenterol. (2016) 51:70210. doi: 10.1007/s00535-015-1144-2

64. Barel F, Auffret A, Cariou M, Kermarrec T, Samaison L, Bourhis A, et al. High reproducibility is attainable in assessing histoprognostic parameters of $\mathrm{pT} 1$ colorectal cancer using routine histopathology slides and immunohistochemistry analyses. Pathology. (2019) 51:46-54. doi: 10.1016/j.pathol.2018.10.007

Conflict of Interest: The authors declare that the research was conducted in the absence of any commercial or financial relationships that could be construed as a potential conflict of interest.

Publisher's Note: All claims expressed in this article are solely those of the authors and do not necessarily represent those of their affiliated organizations, or those of the publisher, the editors and the reviewers. Any product that may be evaluated in this article, or claim that may be made by its manufacturer, is not guaranteed or endorsed by the publisher.

Copyright $\odot 2022$ Gambella, Falco, Benazzo, Osella-Abate, Senetta, Castellano, Bertero and Cassoni. This is an open-access article distributed under the terms of the Creative Commons Attribution License (CC BY). The use, distribution or reproduction in other forums is permitted, provided the original author(s) and the copyright owner(s) are credited and that the original publication in this journal is cited, in accordance with accepted academic practice. No use, distribution or reproduction is permitted which does not comply with these terms. 